\title{
Hair Control during Scalp Surgery Using a Sterile Gel Technique
}

\author{
Jae Kyoung Kang ${ }^{1}$, \\ Myoung Soo Shin', \\ Jung-Kook Song ${ }^{3}$, Byung Min Yun ${ }^{2}$ \\ ${ }^{1}$ Department of Plastic and \\ Reconstructive Surgery, Jeju National \\ University Hospital, Jeju; ${ }^{2}$ Department of \\ Plastic and Reconstructive Surgery, Jeju \\ National University School of Medicine, \\ Jeju; ${ }^{3}$ Department of Preventive Medicine, \\ Jeju National University School of \\ Medicine, Jeju, Korea
}

No potential conflict of interest relevant to this article was reported.
It is necessary to organize and arrange the hair before performing surgery on the scalp. The hair is preserved in most cases, and the remaining hair makes it difficult to apply and maintain the drape. Moreover, hair that has not been properly sterilized can be a risk factor for infection. Accordingly, the authors of the present study benchmarked a method of hair control within the operative field using a sterile gel. Prior to surgery, the hair around the lesion can be organized and rearranged to the desired shape by using a sterile medical gel as a hairstyling product. Subsequently, chlorhexidine-isopropyl alcohol can be used for aseptic skin preparation, followed by draping for surgery. By controlling the hair using this method, hair can be prevented from falling into the operative field, thereby reducing the risk of surgical site infection.

Keywords Preoperative care, Surgical drapes, Surgical wound infection

\section{INTRODUCTION}

When performing surgery on a mass or scar on the scalp, it is a common practice to preserve the hair for aesthetic reasons, unless doing otherwise is unavoidable. However, hair that is not properly sterilized may increase the risk of surgical site infection, and the remaining hair makes draping more difficult and time-consuming. Moreover, the hair may fall into the operative field during surgery, meaning that the position of the drape may also need to change [1]. To address these issues, various methods have been designed and are being used [1-5].

The authors of the present study benchmarked a method of draping using a sterile medical gel, and report a method of using chlorhexidine-isopropyl alcohol as an antiseptic agent for reducing surgical site infections. This method is noteworthy because it allowed the hair to be controlled easily in the operative field during

Received: Sep 7, 2017 Revised: Oct 13, 2017 Accepted: Nov 6, 2017 Correspondence: Byung Min Yun Department of Plastic and Reconstructive Surgery, Jeju National University School of Medicine, 15 Aran 13-gil, Jeju 63241, Korea.

E-mail: almostfree@hanmail.net

Copyright @ 2018 The Korean Society for Aesthetic Plastic Surgery.

This is an Open Access article distributed under the terms of the Creative Commons Attribution Non-Commercial License (http://creativecommons.org/licenses/by-nc/4.0/) which permits unrestricted non-commercial use, distribution, and reproduction in any medium, provided the original work is properly cited. $\quad w w w . e-a a p s . o r g$ surgery, potentially helping prevent postoperative infections.

\section{IDEAS}

Using hairstyling products, such as hair wax, gel, and mousse, can allow the user to hold his or her hair in a desired shape for several hours. Medical gel materials have a certain level of viscosity, which allows them to style and hold the hair in a desired shape, similarly to hairstyling products. Any gel product with a certain level of viscosity may be used for this purpose. However, in surgical contexts, it is necessary to use sterile products in order to reduce the risk of surgical site infections. Numerous multi-purpose sterile gel materials are available on the market, and among these products, lubricant gels are easy to use.

After making a preoperative design for skin incision on the mass or scar, a sterile lubricant gel was applied to the nearby hair, similarly to how hairstyling products would be applied, to create the desired shape. Next, the surgical area and nearby skin were cleaned with chlorhexidine-isopropyl alcohol for skin preparation, after which an appropriately-sized cover or drape was placed on top of the area that would be operated on (Fig. 1).

\section{DISCUSSION}

Various methods have been designed and used to preoperatively control the hair near the surgical area. Such methods include cut- 

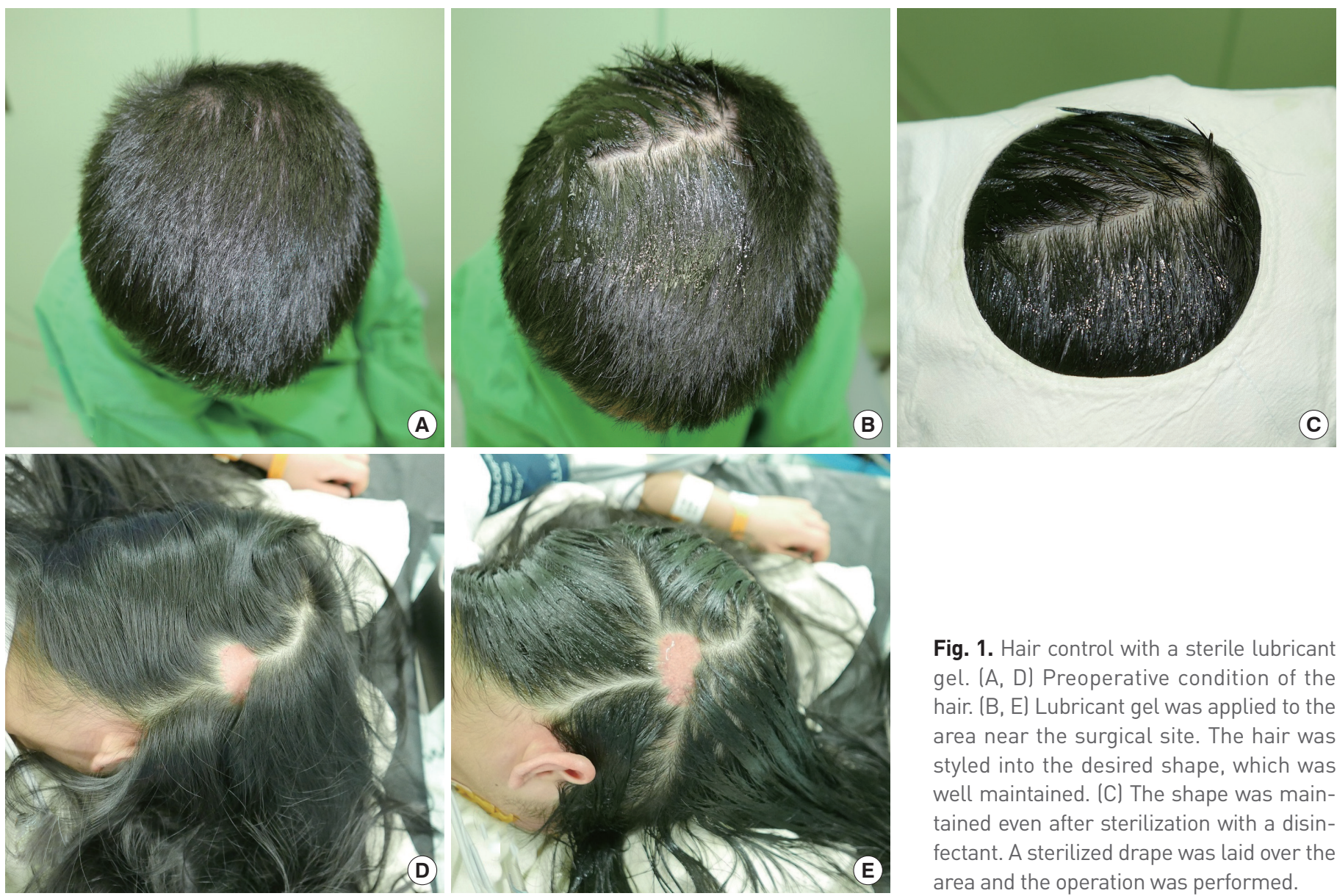

Fig. 1. Hair control with a sterile lubricant gel. (A, D) Preoperative condition of the hair. (B, E) Lubricant gel was applied to the area near the surgical site. The hair was styled into the desired shape, which was well maintained. (C) The shape was maintained even after sterilization with a disinfectant. A sterilized drape was laid over the area and the operation was performed.

ting or shaving the hair prior to the operation, using a hair removal cream to remove the hair, dividing the hair into sections and tying it with rubber bands or clips, using a wet gauze and skin stapler to cover the hair, and leaving the hair as it is [1-5]. None of these methods have been shown to result in a statistically significant difference in surgical site infection rates [6]. Therefore, considering the psychological impact on the patient, aesthetic considerations, and patient satisfaction, it would be best not to remove the hair when possible.

In 2012, Oleszkowicz et al. [7] used sterile gel on fresh surgical wounds to reduce the risk of infection associated with ultrasound transmission gel and recommended the use of nonsterile gel on intact skin. In 2007, Salasche et al. [5] introduced various methods using scissors, expandable mesh gauze, antibiotic ointments, and mousse gel for hair control. However, no explanation was provided of the type of mousse gel used, the sterilization process, or operative field preparation, and no information was provided about the surgical site infections resulting from such factors. Decontamination of the skin with an antiseptic agent is a standard practice for transcutaneous invasive procedures. Although various types of antiseptic agents, including povidone-iodine aqueous solution, iodine in alcohol, aqueous chlorhexidine, chlorhexidine in alcohol, and
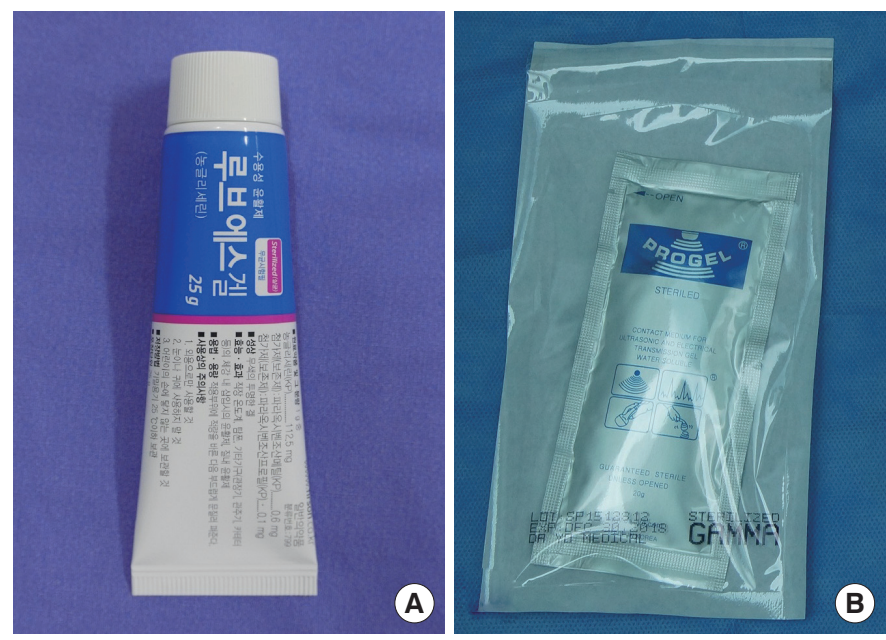

Fig. 2. Two types of sterile medical gel materials: (A) medical lubricant gel, (B) ultrasound transmission gel.

alcohol are currently in use, debates continue about which is best for reducing surgical site infections [8]. However, alcohol-based agents are more effective than aqueous agents for reducing surgical site infections, and chlorhexidine-isopropyl alcohol has been re- 
ported to show better skin sterilization in surgical areas involving a clean wound [9]. Accordingly, the authors of the present study benchmarked a method of using gel materials for hair control near the operative field, similar to the method reported by Salasche et al. [5], and determined that using a sterile gel for hair control and preparing the surgical site with chlorhexidine-isopropyl alcohol could reduce the risk of surgical site infections.

Tying the patient's hair requires substantial preparation time, and it is difficult to use this method when the patient has short hair. Covering the hair with gauze and a skin stapler may allow the hair to fall into the operative field during surgery, thereby requiring additional steps to hold the hair. However, the method used by the authors of the present report allows the hair to be controlled quickly and easily. Moreover, this method can be applied easily regardless of hair length, and it allows the hair to be controlled again by simply reapplying the sterilized gel, even during the operation.

The sterile medical gel materials that could be used in this method include medical lubricant gel, ultrasound transmission gel, and electrical transmission gel (Fig. 2). Although medical gels have been developed for various purposes, they are all mostly made of water, glycerin, propylene glycol, carbomer, hypromellose, and a small amount of preservative. Because these materials have a certain level of viscosity, they can be used to style and hold the hair in the desired shape. Moreover, sterilized single-dose products have become commercially available; these products are readily available in operating rooms and have a low cost.

By using the method described in this article, draping can be performed after controlling the hair in an easy, fast, and safe manner. This method can also help prevent the hair from falling into the operative field during surgery and may reduce the risk of surgical site infections. Moreover, the medical gels that can be used in this method are readily available and affordable. The authors of the present report are introducing this method because it is useful and has many advantages.

\section{PATIENT CONSENT}

Patients provided written consent for the use of their images.

\section{REFERENCES}

1. Nagasao T. A draping technique for scalp operations. J Plast Reconstr Aesthet Surg 2009;62:142-3.

2. Chan WY, Laitung JK. Hair control: a quick and simple method-reply to 'A draping technique for scalp operations' and 'Secure sterile head drape for head and neck surgery. J Plast Reconstr Aesthet Surg 2010; 63:e87-8.

3. Amin N, Fu B, Rutka J, et al. Stapled double head and neck drape for otological procedures. J Laryngol Otol 2013;127:1139-40.

4. Masud D, Gilbert P. Secure sterile head drape for head and neck surgery. J Plast Reconstr Aesthet Surg 2009;62:143-4.

5. Salasche SJ, Orengo IF, Siegle RJ. Dermatologic surgery tips and techniques. Philadelphia, PA: Mosby Elsevier; 2007.

6. Shi D, Yao Y, Yu W. Comparison of preoperative hair removal methods for the reduction of surgical site infections: a meta-analysis. J Clin Nurs 2017;26:2907-14.

7. Oleszkowicz SC, Chittick P, Russo V, et al. Infections associated with use of ultrasound transmission gel: proposed guidelines to minimize risk. Infect Control Hosp Epidemiol 2012;33:1235-7.

8. Dumville JC, McFarlane E, Edwards P, et al. Preoperative skin antiseptics for preventing surgical wound infections after clean surgery. Cochrane Database Syst Rev 2013;3:CD003949.

9. Sidhwa F, Itani KM. Skin preparation before surgery: options and evidence. Surg Infect (Larchmt) 2015;16:14-23. 